International Journal of Humanities and Applied Social Science (IJHASS)

E-ISSN: 2471-7576

May 2020, Vol: 5, Issue: 5

E-mail: editor@ijhassnet.com

http://ijhassnet.com/

DOI: 10.33642/ijhass.v5n5p1

(C)enter for Promoting Education and Research (CPER) USA, www.cpernet.org

\title{
MENTAL HEALTH COUNSELLING SEEKING BEHAVIOUR AND PSYCHOLOGICAL ADJUSTMENT AMONG UNDERGRADUATE STUDENTS IN EKITI STATE, NIGERIA
}

\author{
DR IBIMILUYI, Francis Olu \\ Department of Guidance and Counselling, \\ Faculty of Education, \\ Ekiti State University, Ado-Ekiti, Ekiti State \\ Nigeria
}

\section{ABSTRACT}

The study investigated the mental health counseling seeking behavior and psychological adjustment among undergraduate students in Ekiti State, Nigeria. The study adopted a descriptive research design of the survey type. The population of the study consisted of all undergraduate students in universities in Ekiti State, Nigeria. The sample for this study consisted of 500 undergraduate students from two universities in Ekiti State selected using a multi-stage sampling procedure. Data was collected with the use of a self-designed questionnaire tagged Mental Health Counselling and Psychological Adjustment Questionnaire (MHCPAQ). The instrument was validated through thorough screening by experts of Tests and Measurement with background knowledge in Counselling. The reliability of the instrument was determined by finding the internal consistency of the instrument using Cronbach alpha which yielded reliability co-efficient values of 0.91 for section $B$ and 0.84 for Section $C$. Descriptive and inferential statistics were used to analyze the data collected from respondents. The findings of this study showed that the level of mental health counseling seeking behavior among undergraduate students was low while psychological adjustment was moderate. It was also revealed that mental health counseling seeking behavior of undergraduate students was related to their psychological adjustment. In addition, mental health counseling seeking behavior among undergraduate students does not differ based on their gender but male undergraduate students have higher psychological adjustment than female undergraduate students. Based on the findings, it was recommended among others that university counselors should sensitize undergraduate students on the need to inculcate mental health counseling seeking behavior.

\section{Keywords: Mental Health Counselling, Behaviour, Psychological Adjustment, Undergraduate Introduction}

Psychological adjustment is the emotional expression of maturity and positive inter-personal relationship by an individual. Mangal (2007) defined it as the coping strategy of humans in coming to terms with his or her emotions, behaviors, wellness, and mental reasoning. Relating psychological adjustment to temperament, Ikejiaku, and Ayebami (2006) defined it as affirmative emotional behaviors that empower a person to live amicably in his social environment. It appears that psychologically adjusted undergraduate students will easily incorporate into the university system to achieve the crux of being in an institution of learning. Attributes of such psychologically adjusted students are diligence, good self-esteem, love, co-operative, pleasant, and rational.

When an undergraduate student is proficient in striking such balance in his or her daily undertakings in the school, such an undergraduate student is said to have attained psychological adjustment. A psychologically adjusted undergraduate student has a stable emotion and does not exhibit actions like fighting, anxiety, or aggression. The psychologically adjusted student has internalized control over his emotions and also has good self-esteem. Psychologically adjusted undergraduate students have a very good self-concept. They know how to cope with disappointments and can also influence their environment positively.

Divergently, a psychologically maladjusted undergraduate student may cultivate feelings of helplessness which may lead to forming negative attitudes towards other students and school works. Olayinka (2005) pointed out that psychological maladjustment among undergraduate students may be manifested in drunkenness, anxiety, bitterness, lack of affection, worry, sexual abuse, poor academic performance among others. There seems to be a maladjustment problem common in Nigerian universities and little attention seems to have been given to it. The researcher observed that some undergraduate students experience psychological problems and adjusting seems to be difficult due to their mental health counseling seeking behavior. 
Personal experience of the researcher shows an increase in the cases of psychologically maladjusted undergraduate students in the university especially in areas of annoyance, anger, anxiety, avoiding lectures, examination malpractice, fighting, and other school offenses. Due to this psychological challenge that some undergraduate students have been experiencing in universities, it appears that their mental health is not sound.

Counselling has been theorized as a program of activities which has provided us with the way out of the existing frequent problems in our present age of complex scientific and technological development (Alemu,2013). Counseling services are designed to address the physical, emotional, social, and psychological problems of undergraduate students. Counseling plays a vital role in preventing psychological, emotional, and other similar problems among undergraduate students. Counseling seeking behavior of undergraduate students makes them aware and has understood which empowers them to adjust psychologically. It is a progressive course whereby individuals support others by promoting their development (Alemu,2013). It appears that counseling seeking behavior has a very important function in avoiding emotional, psychological, and other related difficulties among undergraduate students. It seems that the psychological behavior of undergraduate students can be managed through mental health counseling. Mental health counseling focuses on the emotional wellness of an individual. Mental health counseling helps individuals cope with challenging life events. Mental health disorders could lead to psychological maladjustment and good mental health counseling seeking behavior seems to be one of the best ways to tackle the causes of mental disorder. An individual must have good counseling seeking behavior because counseling for mental health involves step by step process that requires time.

Gender can also be a factor that influences mental health-seeking behavior and psychological adjustment. It appears that the female gender is more unadventurous than the male gender that is exposed and outgoing. The study investigated the mental health counseling seeking behavior and psychological adjustment among undergraduate students in Ekiti State, Nigeria. The study specifically examined:

i. the level of mental health counseling seeking behavior among undergraduate students;

ii. the extent of psychological adjustment among undergraduate students;

iii. relationship between mental health counseling seeking behavior and psychological adjustment of undergraduate students;

iv. gender difference in mental health counseling seeking behavior among undergraduate students; and

v. gender difference in undergraduate students' psychological adjustment.

\section{Research Questions}

The following research questions were raised to guide the study:

1. What is the level of mental health counseling seeking behavior among undergraduate students in Ekiti State, Nigeria?

2. What is the extent of psychological adjustment among undergraduate students in Ekiti State, Nigeria?

\section{Research Hypotheses}

The following null hypotheses were generated for this study:

1. There is no significant relationship between mental health counseling seeking behavior and psychological adjustment of undergraduate students.

2. There is no significant gender difference in mental health counseling seeking behavior among undergraduate students.

3. There is no significant gender difference in undergraduate students' psychological adjustment

\section{Methodology}

The descriptive research design of the survey type was utilized to investigate mental health counseling seeking behavior and psychological adjustment among undergraduates. The population of the study consisted of all undergraduate students in universities in Ekiti State, Nigeria. The sample for this study consisted of 500 undergraduate students from two universities in Ekiti State selected using a multi-stage sampling procedure.

The first stage involved the selection of 2 universities through a stratified random sampling technique so that one private university and one public university are selected. In stage two, two faculties were selected from each of the universities through simple random sampling techniques while in stage three, five departments were selected from 
each of the faculties via a simple random sampling technique. In stage four which is the last stage, 25 students were selected from each of the departments using a stratified random sampling technique.

Data was collected with the use of a self-designed questionnaire tagged Mental Health Counselling and Psychological Adjustment Questionnaire (MHCPAQ). The questionnaire was divided into three sections which are A, B, and C. Section A sought for demographic data of respondents; Section B consisted of 10 items on mental health counseling seeking behavior while Section C consisted of 10 items and sought for information on undergraduate students' psychological adjustment. Sections B and C of the instrument was prepared using 4 points Likert type scale as follows: Strongly Agree (SA), Agree (A), Disagree (D) and Strongly Disagree (SD).

The instrument was subjected to face and content validity through thorough screening by experts of Tests and Measurement with background knowledge in Counselling. In so doing, all ambiguous items were eliminated. The reliability of the instrument was determined by finding the internal consistency and data collected were tested using Cronbach alpha which yielded reliability co-efficient values of 0.91 for section B and 0.84 for Section C.

Descriptive and inferential statistics were used to analyze the data collected from respondents. The research questions were answered using frequency count percentages and mean. All hypotheses were tested using Pearson's Product Moment Correlation and t-test analysis at 0.05 level of significance.

\section{Results}

\section{Descriptive Analysis}

Research Question 1: What is the level of mental health counseling seeking behavior among undergraduate students in Ekiti State, Nigeria?

Table 1: Level of Mental Health Counselling Seeking Behaviour

\begin{tabular}{|l|c|c|}
\hline $\begin{array}{l}\text { Level of mental health counselling } \\
\text { seeking behaviour }\end{array}$ & No of Respondents & Percentage \\
\hline Low $(10.00-16.65)$ & 358 & 71.6 \\
\hline Moderate $(16.66-30.12)$ & 129 & 25.8 \\
\hline High $(30.13-40.00)$ & 13 & 2.6 \\
\hline Total & $\mathbf{5 0 0}$ & $\mathbf{1 0 0}$ \\
\hline
\end{tabular}

Table 1 revealed the level of mental health counseling seeking behavior among undergraduate students. The mean score and standard deviation of the responses were used to determine the levels as low, moderate, or high. The low level of mental health counseling seeking behavior was determined by subtracting the standard deviation from the mean score $(23.39-6.74=16.65)$. The moderate level of mental health counseling seeking behavior was determined by the mean score (23.39) while the high level of mental health counseling seeking behavior was determined by adding the mean score and standard deviation $(23.39+6.74=30.13)$. Therefore, a low level of mental health counseling seeking behavior starts from 10.00 to 16.65 , the moderate level starts from 16.66 to 30.12 and the high level of mental health counseling seeking behavior is from 30.13 to 40.00. The findings showed that the level of mental health counseling seeking behavior among undergraduate students in Ekiti State, Nigeria was low. Figure I further revealed the level of mental health counseling seeking behavior at a glance. 


\section{E-ISSN: $2471-7576$}

May 2020, Vol: 5, Issue: 5

E-mail: editor@ijhassnet.com

http://ijhassnet.com/

DOI: 10.33642/ijhass.v5n5p1

(C) Center for Promoting Education and Research (CPER) USA, www.cpernet.org

\section{Percentage}

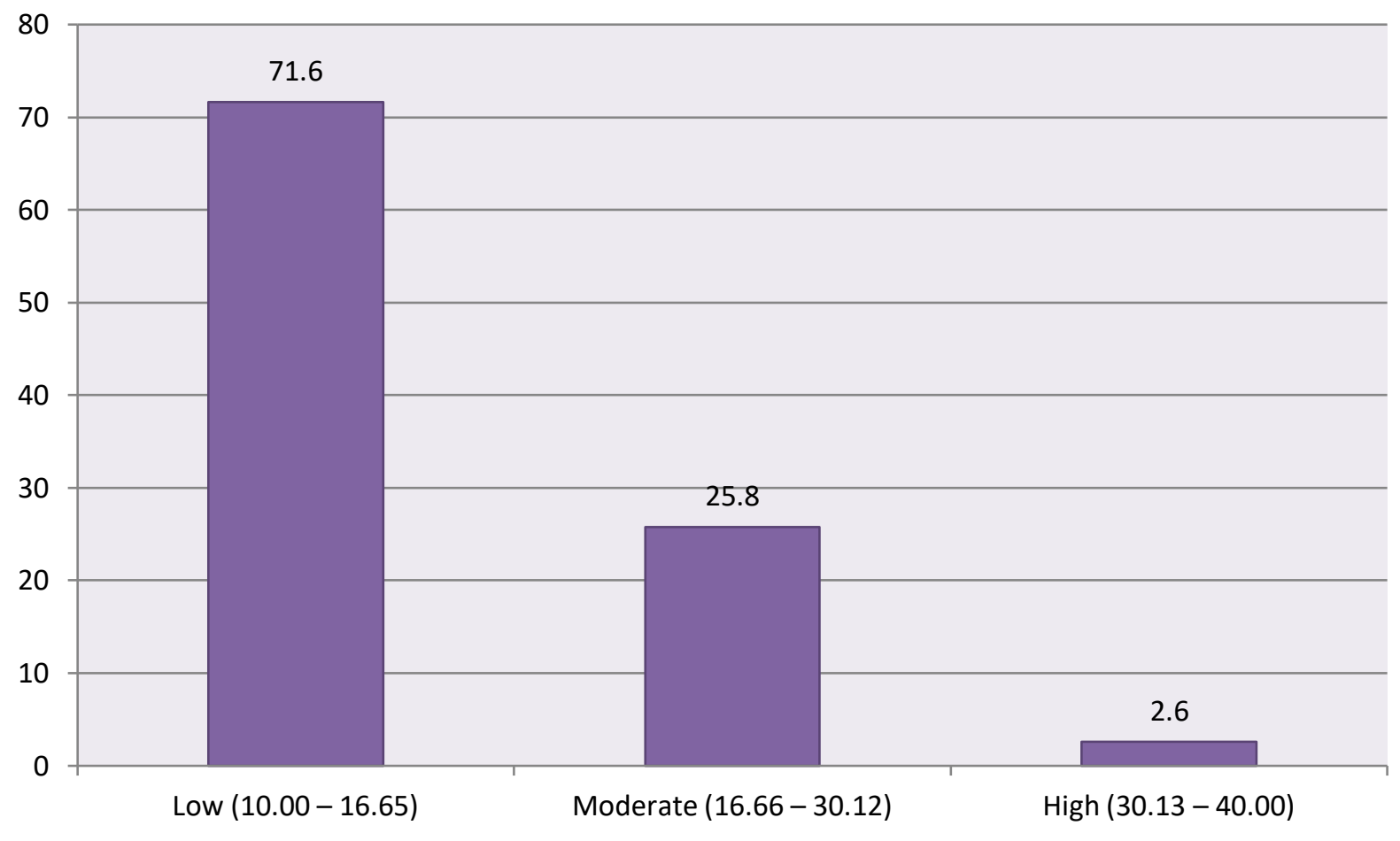

Figure i: Bar Chart Showing level of mental health counselling seeking behaviour

Research Question 2: What is the extent of psychological adjustment among undergraduate students in Ekiti State, Nigeria?

Table 2: Extent of Psychological Adjustment

\begin{tabular}{|l|l|l|}
\hline Extent of psychological adjustment & No of Respondents & Percentage \\
\hline Low $(10.00-24.87)$ & 138 & 27.6 \\
\hline Moderate $(24.88-33.20)$ & 321 & 64.2 \\
\hline High $(33.21-40.00)$ & 41 & 8.2 \\
\hline Total & $\mathbf{5 0 0}$ & $\mathbf{1 0 0}$ \\
\hline
\end{tabular}

Table 2 revealed the extent of psychological adjustment experienced by the respondents. The mean score and standard deviation of the responses were used to determine the levels as low, moderate, or high. The low extent of psychological adjustment was determined by subtracting the standard deviation from the mean score $(29.04-4.17=$ 24.87). The moderate extent of psychological adjustment was determined by the mean score (29.04) while the high extent of psychological adjustment was determined by adding the mean score and standard deviation $(29.04+4.17=$ 33.21). Therefore, the low extent of psychological adjustment starts from 10.00 to 24.87 , the moderate level starts from 24.88 to 33.20 and the high extent of psychological adjustment is from 33.21 to 40.00 . The findings showed that the extent of psychological adjustment among undergraduate students in Ekiti State, Nigeria was moderate. Figure I further revealed the extent of psychological adjustment at a glance. 


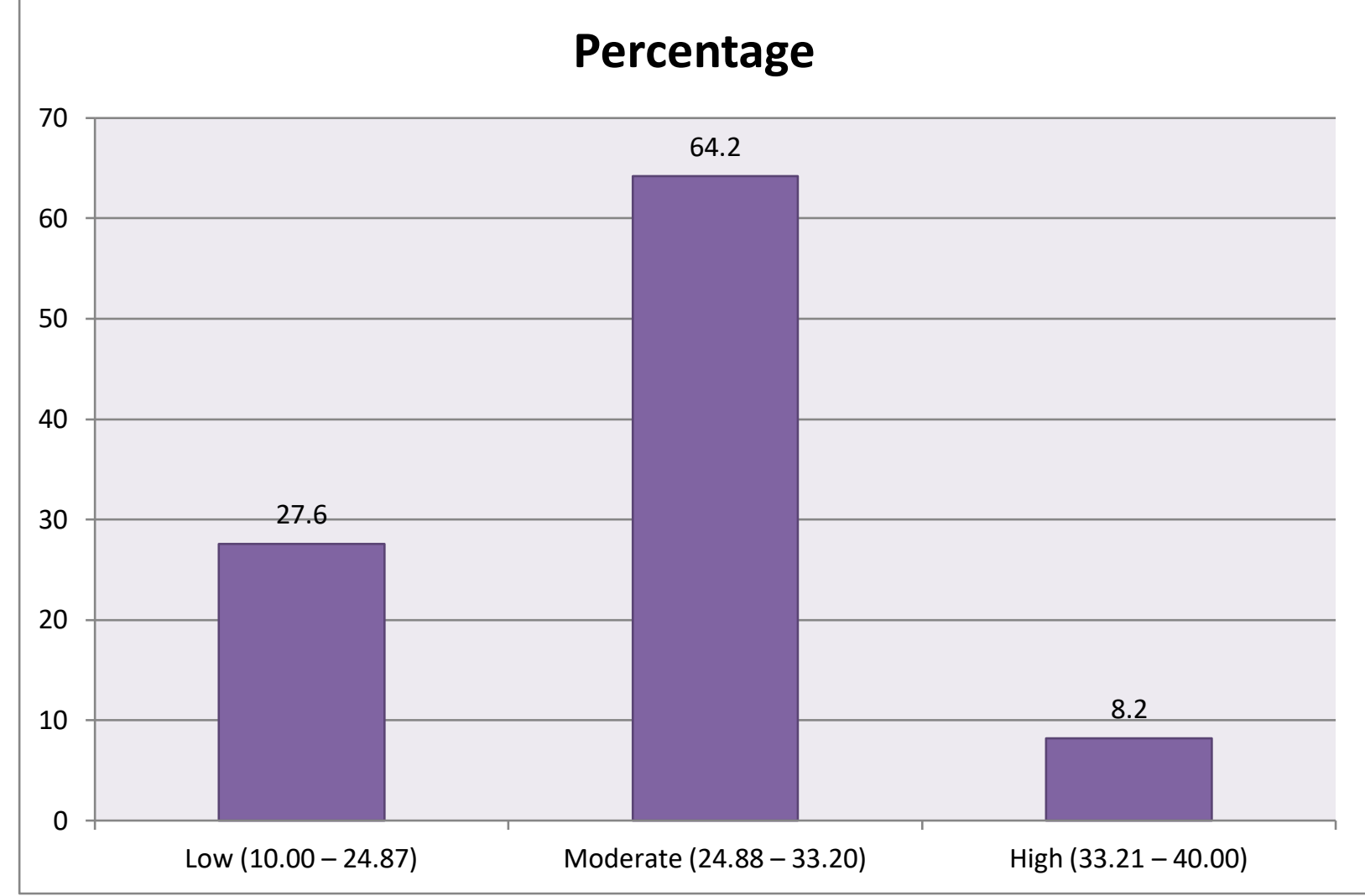

Figure ii: Bar Chart Showing extent of psychological adjustment among undergraduates

\section{Testing of Hypotheses}

Hypothesis 1: There is no significant relationship between mental health counseling seeking behavior and psychological adjustment of undergraduate students.

Table 3: Relationship between mental health counselling seeking behaviour and psychological adjustment

\begin{tabular}{|l|l|r|r|l|r|}
\hline Variables & N & Mean & Stand Dev & r-cal & P-value \\
\hline $\begin{array}{l}\text { Mental Health Counselling Seeking } \\
\text { Behaviour }\end{array}$ & 500 & 23.39 & 6.74 & & \\
\cline { 1 - 4 } Psychological Adjustment & 500 & 29.04 & 4.17 & & $0.401 *$ \\
\cline { 1 - 4 }
\end{tabular}

$$
* \mathrm{P}<0.05
$$

Table 3 showed that the $r$-cal value of 0.401 was significant at 0.05 level because the $\mathrm{P}$-value $(0.000)<0.05$. The null hypothesis is rejected. This implies that there is a significant relationship between mental health counseling seeking behavior and psychological adjustment of undergraduate students. This implies that mental health counseling seeking behavior is moderately related to the psychological adjustment of undergraduate students.

Hypothesis 2: There is no significant gender difference in mental health counseling seeking behavior among undergraduate students.

Table 4: t-test analysis for gender difference in mental health counselling seeking behaviour

\begin{tabular}{|l|l|l|l|l|l|l|}
\hline Variations & N & Mean & SD & df & $\mathbf{t}_{\text {cal }}$ & P \\
\hline Male & 274 & 23.42 & 5.79 & \multirow{2}{*}{498} & 0.130 & \multirow{2}{*}{0.806} \\
\hline Female & 226 & 23.35 & 6.14 & & & \\
\hline \multicolumn{2}{|l|}{$\mathrm{P}>0.05$}
\end{tabular}


Table 4 shows that the $t$-cal value of 0.130 is not significant because the P-value $(0.806)>0.05$. This implies that the null hypothesis is not rejected. Hence, there no significant gender difference in mental health counseling seeking behavior among undergraduate students.

Hypothesis 3: There is no significant gender difference in undergraduate students' psychological adjustment

Table 5: t-test analysis for gender difference in undergraduates' psychological adjustment

\begin{tabular}{|l|l|l|l|l|l|l|}
\hline Variations & $\mathbf{N}$ & Mean & SD & df & $\mathbf{t}_{\text {cal }}$ & $\mathbf{P}$ \\
\hline Male & 274 & 31.72 & 4.04 & \multirow{2}{*}{498} & \multirow{2}{*}{$13.712 *$} & \multirow{2}{*}{0.00} \\
\hline Female & 226 & 26.41 & 4.52 & & & \\
\hline
\end{tabular}

$* \mathrm{P}<0.05$

Table 5 shows that the t-cal value of 13.712 is significant because the P-value $(0.00)<0.05$. This implies that the null hypothesis is rejected. Hence, there is a significant gender difference in undergraduate students' psychological adjustment. There was a mean difference of 5.31 in favor of male undergraduate students; this implies that male undergraduate students have higher psychological adjustment than female undergraduate students.

\section{Discussion}

The findings of the study revealed that the level of mental health counseling seeking behavior among undergraduate students was low. The probable reason for this finding might be as a result of inadequate counseling services in some of our universities. The study also showed that the extent of psychological adjustment among undergraduate students was moderate. This finding is in line with the findings of Sharma and Saine (2013) and Okorodudu and Okorodudu (2013) who submitted that students were moderately adjusted psychologically.

The study further showed that there was a significant relationship between mental health counseling seeking behavior and psychological adjustment of undergraduate students. This implies that as mental health counseling seeking behavior increases, psychological adjustment of undergraduate students will increase. In line with this finding, Auni, Songok, Odhiambo, and Lyanda (2014), Alemu (2013), and Ng'eno (2012) found that mental health counseling seeking behavior was related to psychological adjustment. Contrary to this finding, Ndirangu (2007) found that mental health counseling behavior was not significantly related to psychological adjustment. It could be inferred that when undergraduate students have mental health counseling seeking behavior, there will be an improvement in their psychological adjustment.

The study, however, revealed that there was no significant gender difference in mental health counseling seeking behavior among undergraduate students. This implies that there is no difference in mental health counseling seeking behavior between male and female undergraduate students. This finding is in line with the submission of Auni, Songok, Odhiambo, and Lyanda (2014) who concluded that mental health counseling seeking behavior of male and female students was at the same level.

The study showed that there was a significant gender difference in undergraduate students' psychological adjustment. Male undergraduate students have higher psychological adjustment than female undergraduate students. This finding agrees with the submission of Alemu (2013) who found a gender difference in students' psychological adjustment in favor of male students.

\section{Summary of Major Findings}

The following are the major findings of the study:

1. The level of mental health counseling seeking behavior among undergraduate students in Ekiti State, Nigeria was low.

2. The extent of psychological adjustment among undergraduate students in Ekiti State, Nigeria was moderate

3. There was a significant relationship between mental health counseling seeking behavior and psychological adjustment of undergraduate students.

4. There was no significant gender difference in mental health counseling seeking behavior among undergraduate students.

5. There was a significant gender difference in undergraduate students' psychological adjustment 


\section{Conclusion}

It can be concluded from the findings of this study that the level of mental health counseling seeking behavior among undergraduate students was low while psychological adjustment was moderate. It was also concluded that mental health counseling seeking behavior is very effective in ensuring the psychological adjustment of undergraduate students in universities as mental health counseling seeking behavior of undergraduate students was related to their psychological adjustment. Also, mental health counseling seeking behavior among undergraduate students does not differ based on their gender but male undergraduate students have higher psychological adjustment than female undergraduate students.

\section{Recommendations}

The following recommendations were made based on the findings of the study.

1. Because of the moderate extent of psychological adjustment among undergraduate students, mental health counseling seeking behavior among students should be encouraged by counselors in the school community.

2. University counselors should sensitize undergraduate students on the need to inculcate mental health counseling seeking behavior.

3. University counselors should regularly follow-up undergraduate students after the use of counseling services to ensure their psychological adjustment.

\section{References}

Alemu, Y. (2013). Assessment of Provision of Guidance and Counselling Services in Secondary Schools of East Harerge Zone and Hareri Region, Ethiopia. Middle Eastern and African Journal of Educational Research, (2), 28-37.

Auni, R. T., Songok, R. J., Odhiambo, O. R. \& Lyanda, J. L. (2014). Determinants of Guidance and Counselling Programme in Addressing Students' Social Adjustment in Secondary Schools in Siaya District, Kenya. International Journal of Humanities and Social Sciences, 4 (4), 69-76.

Ikejiaku, L.A. \& Ayebami, T.V. (2006). Introduction to guidance and counselling: Principles and ractice. Lagos: Eldona (Nig.) Limited.

Mangal, S. K. (2007). Advanced Educational Psychology. (2nd ed.) New Delhi: Prentice- Hall of India Private Ltd.

Ndirangu, P. N. (2007). The Influence of Guidance and Counselling Programme on psychological adjustment of Selected Public Secondary School Students: A Case of Bahati Division, Nakuru District. Unpublished Master's Thesis. Egerton University.

Ng'eno, G. K. (2012). Teachers' and Students' Perception of the Impact of Guidance and Counselling Programme on the Satisfaction of Selected Needs of Kenyan Secondary School Students. Unpublished D. Phil. Thesis. Moi University, Eldoret.

Okorodudu, R.I., \& Okorodudu, G.M. (2013). Patterns of psychological adjustment among adolescent in Secondary educational institutions in Nigeria. Retrieved from: www.globalacademicgroup.com>pristine

Olayinka, M.S. (2005). Guidance and counselling for Nigerian schools. Lagos: Literamed publications limited.

Olofintoye, T.T. (2008) Integrated classrooms and the psycho-social adjustment of students with hearing impairment and the hearing. International Journal of Sustainable Development. 1(2), 8-14.

Sharma, P. \& Saine, N. (2013). Health, social, psychological and emotional problems of College Students. IOSR Journal of Humanities and Social Science, 14(50, 21-34 